\title{
Development and Use of Parallel Hybrid Electric Vehicle Model with Suitable Modifications and Break-even Analysis
}

\author{
Tarun Kaushik ${ }^{1}$, Nilay Pandey ${ }^{2}$ \\ ${ }^{1}$ Department of Mechanical Engineering, National Institute of Technology Raipur \\ ${ }^{2}$ Department of Mechanical Engineering, National Institute of Technology Raipur
}

\begin{abstract}
Conventional Models of Series and Parallel Hybrid Electric Vehicles have been compared in terms of efficiency and mechanism employed. The common disadvantage of battery discharging in plug-in HEV during long trips has been dealt with by giving three suitable modifications. The increase in mileage has been depicted using calculations. A break-even analysis of slightly expensive modified HEV with percentage improvements in mileage and decrease in fuel costs has been shown.
\end{abstract}

Keywords: HEV, PSD, GEH, Regenerative Braking.

\section{Introduction}

\section{Hybrid Car}

Any vehicle that combines two or more sources of power that can directly or indirectly provide propulsion is a hybrid. Most hybrid cars on the road right now are gasoline-electric hybrids (GEH). In a GEH one source of power is gasoline engine and the other is electric battery.

\section{Advantages of Hybrid Car-}

1) Since the hybrid is a cross between gasoline and electric, the fossil fuel consumption by it is significantly reduced.

2)They are helpful in bringing down the level of greenhouse emissions.

3) Since a hybrid gives us some extra miles for the same quantity of gasoline, they are even more useful as the prices of petroleum are rising very steeply.

Some people put up the argument that fully electric vehicles are even more eco-friendly but since they do not generate necessary torque and have less driving range, HEV provide the best of both worlds experience; the driving range of diesel engines and fuel efficiency, eco-friendliness of electric engines.

Current Scenario of fossil fuel-

The amount of years of fossil fuels left in the world is as follows-

Oil- 32 years

Coal- 107 years

Gas- 37 years

These alarming statistics provoke us to ponder and develop some new technologies that will reduce the consumption of these fuels. HEV are one of them.

\section{Design}

The power train of a Hybrid car can be categorized into two way

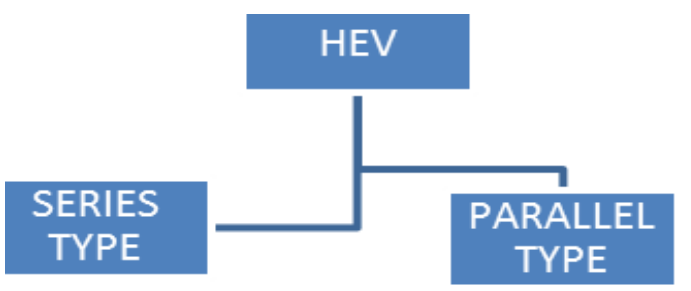

1) Series type - In this type of HEV the gasoline Internal Combustion engine is used to run a generator which generates electricity. This electricity is used to run a motor which drives the shaft. Some part of this electricity is also used for the charging of a battery which provides extra torque at the time of acceleration.

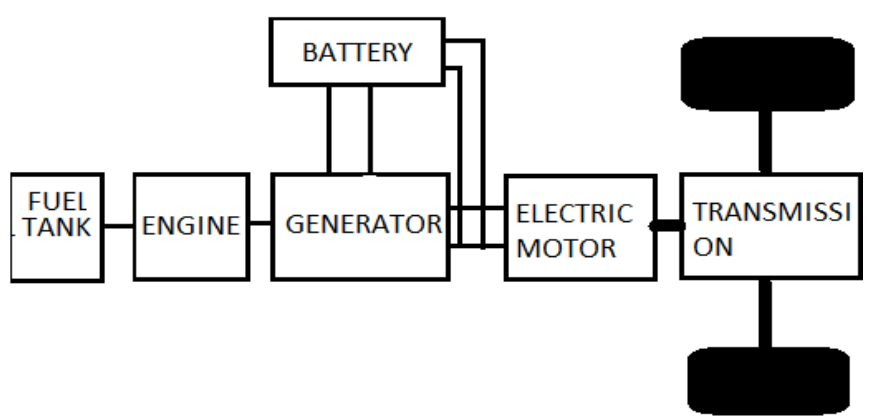

But a very big disadvantage of series type HEV is that since energy from one form is converted to other therefore loss of energy is high.

2) Parallel type -

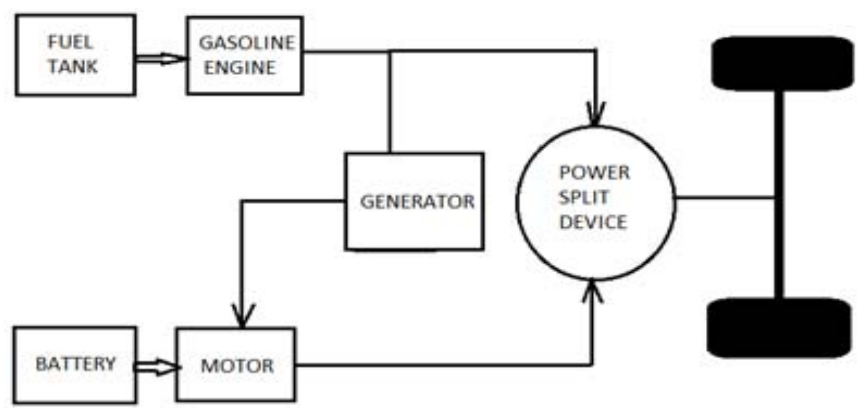




\section{International Journal of Science and Research (IJSR) \\ ISSN (Online): 2319-7064 \\ Index Copernicus Value (2013): 6.14 | Impact Factor (2013): 4.438}

In this type of hybrid, the battery needs to be charged in advanced. Both the IC engine and battery can rotate the shaft together so this is categorized in the parallel type. A device called Power Split Device (PSD) is used for this purpose. In this device the two shafts (one from engine and other from motor) rotating at the same speed but not necessarily the same torque is used to rotate a set of planetary gears. Here the torque adds up and provides necessary power at the output.

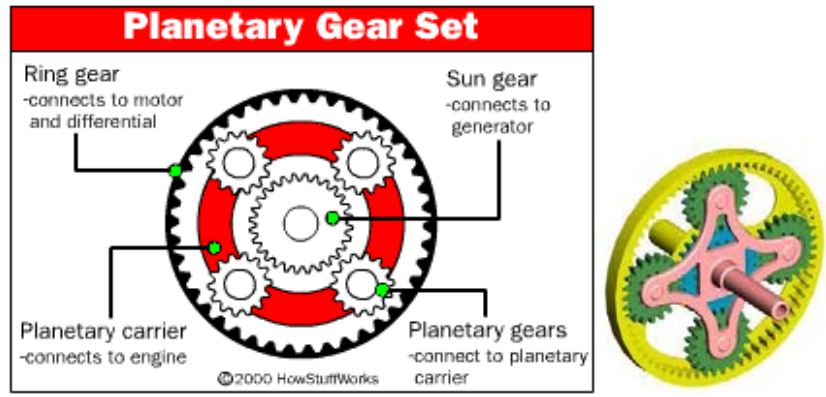

\section{Working}

Since we know that there are two power sources in a HEV, which can drive the shaft simultaneously as well as independently of each other with the help of planetary gears.

- When we start the car it is totally powered by the battery which has been charged in advance. So there is no need of a starter.

- As soon as the car reaches normal cruising speed i.e. $40 \mathrm{kmph}$, the gasoline engine is now running in full flow. A part of the power of gasoline engine is put directly into the PSD and some part of it is transferred to the generator which helps in driving the motor. The motor also sends the generated power to the PSD.

- When high acceleration is required the engine transmits its total power to the wheels by the mechanism defined above and the battery also gets discharged by providing the necessary additional torque.

- While braking or stopping at red-light i.e. when the speed of the vehicle falls below a minimum thresh hold the gasoline engine shuts and battery takes over. Thus this feature is very helpful in saving a lot of fuel and provides the car with a better mileage.

\subsection{Engine Specifications}

The key point in the above design is that since we have coupled the engine and electric motor therefore a lighter engine can be used to generate the same amount of torque as developed in a normal car. This is the biggest advantage as lighter engine means lesser fuel consumption and increased efficiency. Example- The work of a 3 liter engine in normal car is performed by a 1.5 liter engine in a HEV.

\section{Problem Statement}

For a hybrid to be able to replace the conventional cars it must provide greater driving range. Normally the battery gets discharged in 40 miles. After the battery gets discharged the HEV starts taking all its power requirements from the
Gasoline engine. Thus all the advantage of being a hybrid car gets neutralized. So some solutions on how to increase the driving range of a Hybrid Electric vehicle (Parallel Type) are described below.

\section{Modifications}

1) Regenerative Braking -As we know that when a car brakes all the kinetic energy gets of a vehicle gets lost in the form of heat energy when we apply the push brakes. So there is a system called regenerative braking which utilizes the kinetic energy (otherwise lost) in charging the battery.

Working- When the brakes are applied the electronically controlled system detects the change in momentum of the car and rotates the motor (which is rotating the shaft) in the opposite direction. A motor working in the opposite direction acts as a generator and transfers the energy generated to the battery. This in situ charging of the battery increases the time of its discharging.

Normally the efficiency of a car is $20 \%$ ( $80 \%$ is lost). This regenerative breaking system helps in putting half of the energy wasted back into the power train thus reducing the fuel consumption by 10 to $25 \%$. But since, in a long distance trip not much braking is required so it does not fulfill the complete demand. It is very useful while driving in traffic where continuous start and stops are made.

2) Use of Solar Panels - Another method of increasing the range of operation of a hybrid car is to use a solar panel which will charge an additional battery. Thus the frequency required for charging the battery by plugging in is considerably reduced. This is particularly useful while travelling longer distances where the facility of recharging the battery may not be available.

Working- The solar panel can be added on the top of the roof of the car in the form of a convertible roof. If you are going out on a long trip and the sun is in its full flow (not during night), then the driver has the option of taking the convertible roof out and then allow the solar panels to generate electricity. In place of an additional battery we can also use super capacitors which are much smaller in size and are much more efficient in charging. But the cost increase will nullify the advantages gained through increase in efficiency.

Adding solar panels to the parallel HEV helps in saving 10$15 \%$ of the fuel, thus adding some extra miles to the same quantity of gasoline.

3) To use some part of the Power of Gasoline Engine in Charging the Battery- During normal cruising of the car the energy provided by the gasoline engine goes direct to the transmission as well as to the generator. The output of the generator is sent to the motor to propel the car. If we take some electricity out of the generator and use it in charging the battery, it will increase the range of operation.

When we share some power of the motor with the battery, the energy at the output end is compromised. Therefore while 


\section{International Journal of Science and Research (IJSR) \\ ISSN (Online): 2319-7064 \\ Index Copernicus Value (2013): 6.14 | Impact Factor (2013): 4.438}

normal driving in the city traffic regenerative braking is enough for the charging of battery and the above mentioned system is not required.

But for long distance journeys regenerative braking is not enough, so we can provide the driver with an option of switch which will turn on the power sharing of generator with the battery so that it gets charged and complements the regenerative braking system.

The battery is specially designed to receive as well as release power more efficiently. Ni-MH battery is used.

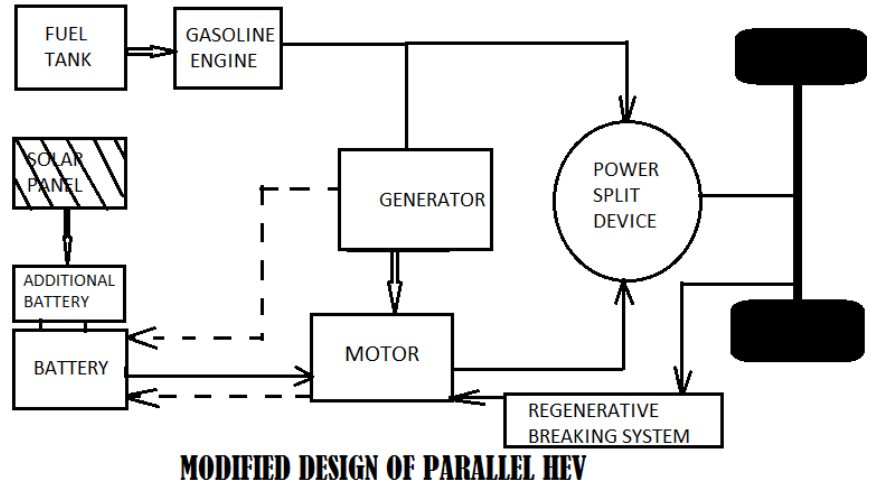

Here dotted line indicates the modified power train that is suggested to improve the performance of battery.

\section{Efficiency Calculations}

\section{Regenerative Braking}

A normal parallel HEV gives an average mileage of

$19.21 \mathrm{~km} / 1-21.67 \mathrm{~km} / 1$.

If regenerative braking system is involved then it is helpful in saving $10-25 \%$ of fuel. We are taking an average fuel saving of $17 \%$ to assist our calculations.

So now the improved mileage of the hybrid equipped with regenerative braking becomes

$(0.17 * 19.21+19.21=22.47) \mathrm{km} / 1$ to

$(0.17 * 21.67+21.67=25.35) \mathrm{km} / \mathrm{l}$

I.e. $22.47 \mathrm{~km} / \mathrm{l}-25.35 \mathrm{~km} / 1$

Use of Solar Panels-

- The roof of a normal sedan can easily provide an area of $2 \mathrm{~m}^{2}$ approximately.

- One solar panel consists of four solar cells (each 5.08*1.27 $\mathrm{cm}$.).

- The total area of the roof of the car provides an area of $20000 \mathrm{~cm}^{2}$. Therefore we can place approx. 775 solar panels.
- Each $\mathrm{cm}^{2}$ area of the solar panel is capable of producing an electric current of $10.8 \mathrm{~mW}$.

- Thus the total solar power generated by the solar panels will be equal to 217 Watt.

- A HEV equipped with solar panels complimented by regenerative braking is thus able to save $10 \%$ of the fuel.

- The mileage of modified HEV will be around $24.71 \mathrm{~km} / 1$ $27.88 \mathrm{~km} / 1$

This technology is even more feasible in the tropical areas because the intensity and angle of incidence of sun rays is greater and is active more part of the year.

After adding all the modifications described above the mileage of the parallel type HEV is considerably enhanced.

Regenerative braking, use of solar panels and use of gasoline engine to charge the battery, when used in HEV can provide a mileage

$$
27-29 \mathrm{~km} / \mathrm{l}
$$

\section{Cost Efficiency Calculations}

Cost of a normal sedan $=₹ 15,00,000$

Cost of the modified hybrid car - ₹ 19,60,000

(Including ₹ 75,000 for the installation of solar panel)

Assuming the mileage to be constant over the years,

Mileage of a normal car $=15 \mathrm{~km} / 1$

Mileage of proposed $\mathrm{HEV}=28 \mathrm{~km} / 1$

Cost of Petrol (approx.) = ₹ 65 per litre

A car is driven on an average $20,000 \mathrm{~km}$. in a year

Cost of petrol in a year for normal car $=₹ 86,670$

Cost of petrol for HEV in a year $=₹ 46,430$

Amount of money saved per year $=₹ 40,240$

Time required for the extra cost of car to made up $=11.43$ years.

\section{Comparison Table}

\begin{tabular}{|c|c|c|c|}
\hline & Normal Car & HEV & $\begin{array}{c}\text { Mileage Improvement } \\
(\%)\end{array}$ \\
\hline $\begin{array}{c}\text { Mileage } \\
(\mathrm{km} / \mathrm{l})\end{array}$ & 15 & 28 & 86.67 \\
\hline & & & Cost Reduction (\%) \\
\hline $\begin{array}{c}\text { Annual Fuel } \\
\text { Cost ( ₹) }\end{array}$ & 86,670 & 46,430 & 46.42 \\
\hline
\end{tabular}




\section{International Journal of Science and Research (IJSR) \\ ISSN (Online): 2319-7064}

Index Copernicus Value (2013): 6.14 | Impact Factor (2013): 4.438

Break-even Analysis

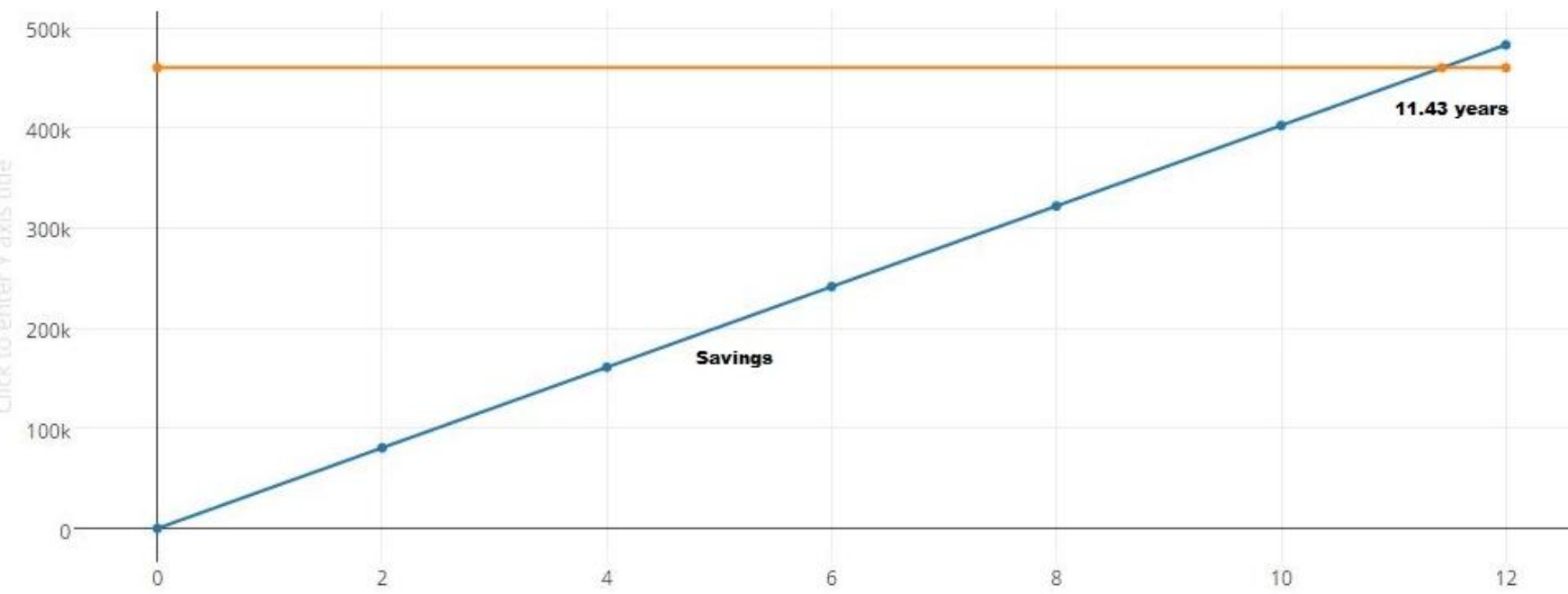

\section{Common Misconceptions}

A general misconception about HEV is that they are slower than normal gasoline powered cars as they use lighter engines. But this is largely untrue because coupling of gasoline engine with electric power provides the same amount of torque and they can easily achieve $161 \mathrm{kmph}$.

Their cost sometimes proves a hindrance for buying them but as shown above in cost efficiency calculations, the extra cost can be made up in almost 11.5 years.

\section{Conclusions}

Since only 32 years of oil are left, therefore it is the need of the hour to look for alternative technologies. HEV started as one of the technologies which can save us fuel crisis, but it has reached a point in its life cycle where it will either take off as a mainstream product or slowly fade away as an obsolete technology. To launch the HEV's into the market of common people it needs some immediate overhauling and the technology described above can certainly help us to achieve this purpose.

\section{References}

[1] Moreno, J. , Ortuzar, M.E. and Dixon, J.W., "Energymanagement system for a hybrid electric vehicle, using ultracapacitors and neural networks", Industrial Electronics, IEEE Industrial Electronics Society, Volume:53, Issue: 2, 614 - 623, April 2006

[2] Yuki Tanaka and Yukio Shegeta, "Upcoming Advances in the Hybrid Vehicle Market", NRI Papers, Nomura Research Institute, No. 114, Feb 12007

[3] Mariam Khan and Narayan C. Kar, "Hybrid Electric Vehicles for Sustainable Transportation: A Canadian Perspective", World Electric Vehicle Journal, Vol. 3 ISSN 2032-6653 , 2009 AVERE

[4] AuYeung, Felix, Elizabeth Drake, John Heywood, Andreas Schafer, and Malcolm Weiss. "On the Road in 2020." Massachusetts Institute of Technology. N.p., n.d. Web (4 November 2009). web.mit.edu/energylab/www/pubs/el00-003.pdf.

[5] Berman, Bradley. "Hybrid Market Forecasts | Hybrid Cars." New Hybrid Reviews, News \& Hybrid Mileage (MPG) Info | Hybrid Cars. 30 Sep. 2009 http://www.hybridcars.com/hybrid-

drivers/hybrid-market-forecasts.html.

[6] Heffner, Reid, Kenneth Kurani, and Thomas Turrentine. "Symbolism in early Markets for Hybrid Electric Vehicles." (2007) Web. 17 Nov. 2009.

[7] LaMonica, Martin. "Most Consumers Willing to Pay for Hybrid Cars." Green Tech 24 June 2008 http://news.cnet.com/8301-11128_3-9976308-54.html.

[8] LaMonica, Martin. "Most Consumers Willing to Pay for Hybrid Cars." Green Tech 24 June 2008 http://news.cnet.com/8301-11128_3-9976308-54.html.

\section{Author Profile}

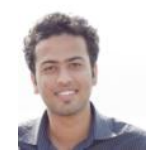

Tarun Kaushik is pursuing his B.Tech in Mechanical Engineering from NIT Raipur and presently is in his fourth year of undergraduate study (2012-16). He is an Automobile Enthusiast and his fields of study are sustainability of resources and marketing of technological innovation. He is currently the Student Vicepresident of SAE NIT Raipur and looking after its marketing and sponsorship vertical.

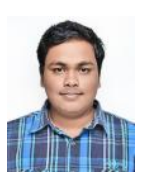

Nilay Pandey is pursuing his B.Tech in Mechanical Engineering from NIT Raipur and presently is in his third year of undergraduate study (2013-17). He is an automobile enthusiast and his fields of interest are sustainable energy, efficiency improvement and utilization, hybrid vehicles. Currently he is an active member of SAE NIT Raipur. 